\title{
Клинико-морфологические сопоставления острых абсцессов легких
}

Алтайский государственный медицинский университет: 656038, Барнаул, пр. Ленина, 40

\section{Ya.N.Shoikhet, A.V.Lepilov, Yu.G.Motin, N.V.Lel \\ Clinical morphology of acute lung abscess}

\begin{abstract}
Summary
The paper has been analyzed results of clinical and pathological investigations of respiratory system in patients with acute lung abscess. Three clinical and morphologic patterns of this pathology have been established. Features of intraalveolar, intravascular and interstitial fibrin deposition in the lungs have been described demonstrated. Particular features of formation and stabilization of fibrin as well as interactions between fibrin and cell populations depending on the clinical variant of acute lung abscess were discovered.

Key words: clinical-and-morphological, lung abscess, sequestration, fibrin formation, type-IV collagen, fibrinolysis, systemic inflammatory response.
\end{abstract}

\section{Резюме}

Анализируются результаты клинического и патоморфологического исследований респираторного отдела больных острыми абсцессами легких, определены 3 клинико-морфологических варианта течения патологического процесса. Показаны особенности интраальвеолярного, интраваскулярного, периваскулярного и интерстициального отложений фибриновых депозитов в респираторном отделе легких. Установлены особенности процессов фибринообразования и фибриностабилизации, а также взаимодействия клеточных популяций с фибриновыми депозитами в зависимости от варианта клинического течения острого абсцесса легкого.

Ключевые слова: клинико-морфологический, абсцесс легкого, секвестрация, фибринообразование, коллаген IV типа, фибринолиз, системная воспалительная реакция.

Высокий уровень заболеваемости острым абсцессом легких (ОАЛ), низкое качество жизни при этой патологии, высокая летальность и инвалидность обусловливают актуальность проблемы лечения [1]. Существует тенденция к росту заболеваемости у лиц молодого и среднего возраста, что немаловажно в социально-экономическом отношении [2].

В настоящее время нет единого мнения о клинических формах острой неспецифической гнойной деструкции легких. Так, ОАЛ с секвестрацией часто описывается как самостоятельная форма процесса $[3,4]$, а в ряде случаев - как форма абсцесса легкого или гангрены [5]. Стоит считать, что он относится к абсцессам, т. к. имеет сформировавшуюся полость, отграниченную от остальных тканей легкого посредством пиогенной мембраны. По течению и исходам он близок к острым абсцессам [6, 7].

Баланс процессов альтерации и репарации в поврежденных тканях легкого невозможен без морфологической перестройки. Проведенные в последние годы клинико-морфологические исследования показали, что характер и течение абсцесса легких во многом определяется реактивностью макроорганизма [8, 9]. Инфекционный агент, инициирующий патологический процесс, действует относительно непродолжительный период времени, и именно нарушения в системе бронхиальной проходимости и / или микроциркуляторного русла определяют особенности и варианты течения заболевания.

Основную барьерную функцию в тканях выполняет фибрин, поскольку только этот белок отличается уникальной динамикой: он способен переходить из растворимого состояния в нерастворимое и наоборот. Благодаря ему ограничивается не только распространение микробов и их токсинов, но, что не менее важно, цитокинов. Отложение фибрина как в микрососудах органа, так и параваскулярно приводит к развитию ишемических и воспалительных нарушений, затрудняет доступ лекарственных препаратов в очаг деструкции, снижает эффективность лечения и вызывает дестабилизацию клеточно-стромальных взаимодействий в очаге поражения. Несостоятельность фибринового блока может привести к прогрессированию воспалительного процесса и вовлечению в него новых анатомических структур легких, что негативно влияет на последующие репаративные процессы [10].

Цель исследования - выявить особенности клинического течения ОАЛ в связи с морфологическими вариантами изменения респираторного отдела.

\section{Материалы и методы}

Исследованы ткани респираторного отдела 97 больных ОАЛ, в т. ч. 69 пациентов с ОАЛ без секвестрации и 28 - с секвестрацией. Возраст пациентов варьировался от 24 до 80 лет (в среднем - 52,00 \pm 1,19 года).

Гистологическую обработку тканей выполняли по общепринятой методике, срезы толщиной 4-6 мкм окрашивали гематоксилином и эозином, пикрофуксином Вейгерта, по Гордону-Свиту, по методу А.Н.Яцковского, проводили реакцию Шика. Для оценки процессов фибринообразования и фибриностабилизации использовали окраску на фибрин, 
по Пикро-Маллори II, и MSB-метод в модификации Д.Д.Зербино [11].

Для определения экспрессии коллагена IV типа и подопланина применяли метод двойной непрямой иммунофлюоресценции. В качестве первичных использовали следующие антитела: моноклональные антитела к коллагену IV типа (C-1926 (Sigma, США) в разведении $1: 100)$, поликлональные антитела кролика к подопланину (P-5374 (Sigma, США) в разведении $1: 10)$. В качестве вторичных антител для визуализации коллагена IV типа использовали Texas-Redмеченые козлиные антитела (XR-9770 (ProSci, США) в разведении $1: 20$, для визуализации подопланина FITS-меченые антитела (F-9887 (Sigma, CША) в разведении $1: 1000$ ). Морфометрические исследования проводили с использованием графических пакетов ImageJ 1.34 [12] и AxioVision 3.1 (Carl Zeiss, Германия).

Полученные данные обрабатывались статистически с использованием компьютерных программ JMP 5.1, SigmaStat 3.10 for Windows. Оценку межгрупповых различий проводили по U-критерию Манна-Уитни или критерию Холма-Сидака при нормальном распределении признака и равенстве дисперсий, сравнение качественных признаков с помощью критерия $\chi^{2}$. За уровень статистической значимости принимали $p<0,05$. Результаты работы представлены в виде значений $M$ (среднее арифметическое) $\pm m$ (ошибка среднего).

\section{Результаты}

Начало заболевания 79 пациентов $(81,4 \%)$ связывали с перенесенным переохлаждением или простудными заболеваниями. Подавляющее большинство из них $(71,4 \%)$ отмечали острое начало заболевания с повышением температуры и появлением кашля.

Клиническая картина характеризовалась болью в груди у $85,7 \%$ больных, кашлем с выделением мокроты - у 94,9\%. Все пациенты жаловались на анорексию, слабость, утомляемость, одышку. У 92,8 \% больных температура тела была повышена. У 55,7 \% температура тела была $37-38{ }^{\circ} \mathrm{C}$, у $30,9 \%-\geq 38^{\circ} \mathrm{C}$. У $67,0 \%$ была потеря массы тела. Содержание белка в плазме крови < 65 г/л было у 29,9\% пациентов. По данным лабораторных методов исследования, у всех больных активность воспалительного процесса была велика: регистрировались высокие показатели СОЭ (> 40 мм/ч - у 48,5 \%, максимальное значение 75 мм/ч), С-реактивного белка, фибриногена, лейкоцитоз, сдвиг лейкоцитарной формулы влево.

У большинства (56,7 \%) больных было поражено правое легкое, левое - реже, у 30 (30,9\%) пациентов. Чаще поражалась нижняя доля правого легкого $(28,9 \%)$; верхние доли правого и левого легких были подвержены патологическим процессам с примерно одинаковой частотой $(11,3 \%$ и $10,3 \%$ соответственно). У 12 (12,4 \%) больных диагностированы 2-сторонние нагноения легких.

Морфологическое исследование позволило выделить у больных острыми абсцессами легких 3 варианта структурной перестройки респираторного отдела. Эти структурные варианты имели отличительные признаки в зависимости от степени выраженности процессов фибринообразования и фибриностабилизации, функционального состояния клеточных популяций воспалительного инфильтрата и характера нарушений микроциркуляторного русла респираторного отдела легких.

1-й морфологический вариант отмечен нами у $58 \%$ больных ОАЛ без секвестрации и у $7,1 \%-$ с секвестрацией. Фокус гнойной деструкции хорошо ограничивался от окружающих тканей "молодыми" фибриновыми депозитами (со сроком фибринообразования от 2 до 48 ч). Воспалительный клеточный инфильтрат содержал $61,80 \pm 2,19 \%$ нейтрофилов, $33,40 \pm 0,97 \%$ макрофагов и $4,76 \pm 0,16 \%$ лимфоцитов. В области фибринового блока наблюдалось формирование микрополостей вокруг клеточных популяций воспалительного инфильтрата. Мембранные рецепторы макрофагов, нейтрофилов и лимфоцитов не блокировались фибриновыми депозитами, и таким образом обеспечивалась возможность выполнения клетками присущих им биологических функций. Функциональную активность сохраняли $61,70 \pm$ $2,21 \%$ макрофагов, $82,10 \pm 3,08 \%$ нейтрофилов и $89,50 \pm 2,39 \%$ лимфоцитов.

Микрососуды в области ограничения острого гнойно-деструктивного очага были полнокровны (рис. 1). В их просвете не было фибриновых депозитов, лишь в единичных случаях в гемокапиллярах наблюдали нежную сеточку "юного" фибрина на поверхности лейкоцитов. Таким образом, проходимость кровеносных сосудов для форменных элементов крови сохранялась. Относительная площадь сечения сосудов составила $14,70 \pm 1,09$ мкм²$^{2}$ количество сосудов на единице площади $-3,45 \pm 0,37$.

Посредством иммуногистохимической верификации коллагена IV типа выявлены локальные участки расщепления и деструкции базальных мембран альвеолоцитов и эндотелиоцитов. Отмечалась фиксация обломков базальных мембран на фибриновом матриксе.

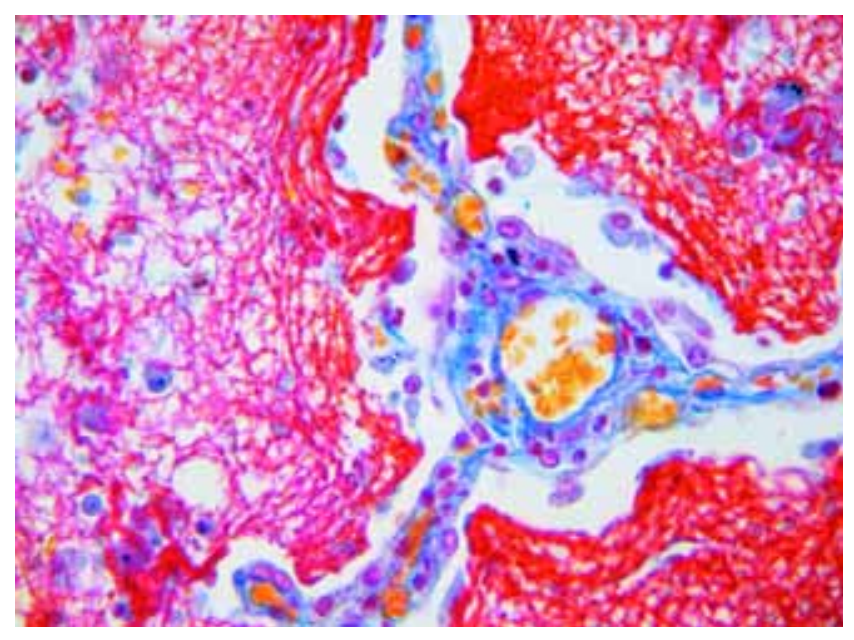

Рис. 1. Свободное расположение клеточных популяций в области "фибринового блока", кровеносные сосуды не блокированы фибрином. Окраска MSB; × 100 


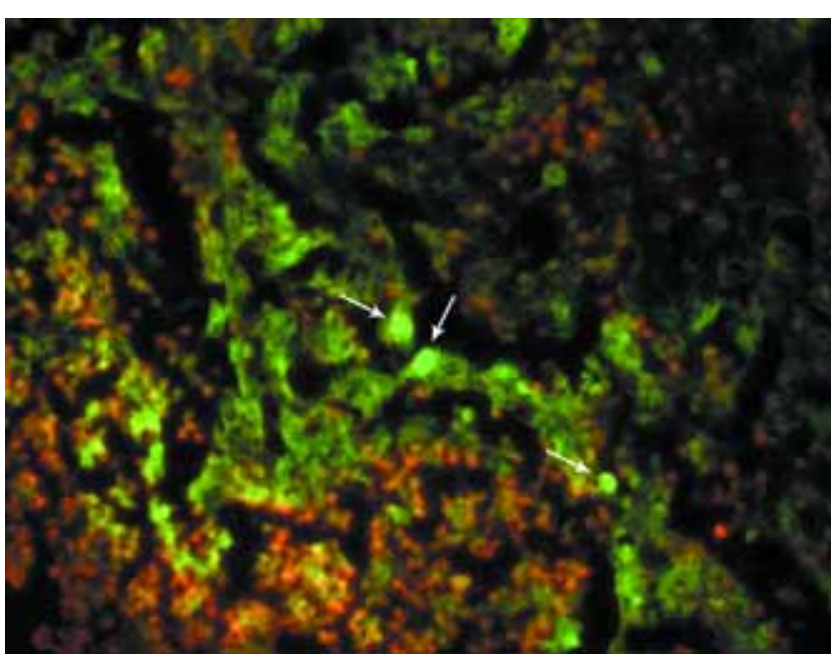

Рис. 2. Фокус гнойной деструкции (внизу слева). Слущивание эндотелиоцитов, деструкция стенки лимфатических микрососудов (стрелки). Расположение коллаген-IV-позитивного материала в фокусе гнойной деструкции и на фибриновом матриксе зоны ограничения. Двойная непрямая иммуногистохимическая реакция на коллаген IV типа (красная иммунофлюоресценция) и подопланин (зеленая иммунофлюоресценция); × 400

Хорошо визуализировались сосуды глубокой лимфатической системы легкого. Наибольшему повреждению подвергались лимфатические сосуды, находившиеся в фокусе гнойной деструкции или на границе с ней (рис. 2). Определялись слущивание эндотелия лимфатических сосудов, деформация и разрушение их стенок. Лимфатические сосуды, расположенные в зоне ограничения и в более удаленных участках, как правило, сохраняли свою морфологическую структуру.

Все больные с представленным вариантом морфологических преобразований респираторного отдела отмечали боли в грудной клетке, кашель. При этом у $1 / 3$ пациентов количество отходившей за сутки мокроты превышало 200 мл. Определялись умеренно выраженные признаки системной воспалительной реакции (SIRS); при этом тахипноэ зарегистрировано у 84,1 \% пациентов, тахикардия отмечена у $60,9 \%$ (таблица).

2-й морфологический вариант наблюдался в подавляющем большинстве случаев $(85,7 \%)$ у больных ОАЛ с секвестрацией и у $26,1 \%$ - без секвестрации.

Таблииа

Связь симптомов ОАЛ и морфологического варианта перестройки респираторного отдела (\%)

\begin{tabular}{|c|c|c|c|c|}
\hline \multirow[t]{2}{*}{ Частота симптомов, \% } & \multicolumn{3}{|c|}{ Морфологический вариант } & \multirow[t]{2}{*}{$p$} \\
\hline & $1-и ̆(n=42)$ & $2-\bar{n}(n=42)$ & 3-й $(n=13)$ & \\
\hline Боль в груди & 100,0 & 57,1 & 100,0 & $<0,001$ \\
\hline Кашель & 100,0 & 100,0 & 100,0 & - \\
\hline $\begin{array}{l}\text { Кашель с мокротой } \\
>200 \text { мл }\end{array}$ & 30,4 & 17,8 & 69,2 & 0,003 \\
\hline Тахипноэ & 84,1 & 32,1 & 76,9 & $<0,001$ \\
\hline Тахикардия & 60,9 & 92,9 & 92,3 & $<0,001$ \\
\hline $\begin{array}{l}\text { Снижение систоличес- } \\
\text { кого АД < } 100 \text { мм рт. ст. }\end{array}$ & 33,3 & 67,8 & 84,6 & $<0,001$ \\
\hline Температура $>38^{\circ} \mathrm{C}$ & 31,9 & 53,6 & 61,5 & 0,041 \\
\hline
\end{tabular}

Примечание: АД - артериальное давление; $p<0,05$ - статистическая значимость раз личий показателей между морфологическими вариантами по критерию $\chi^{2}$.

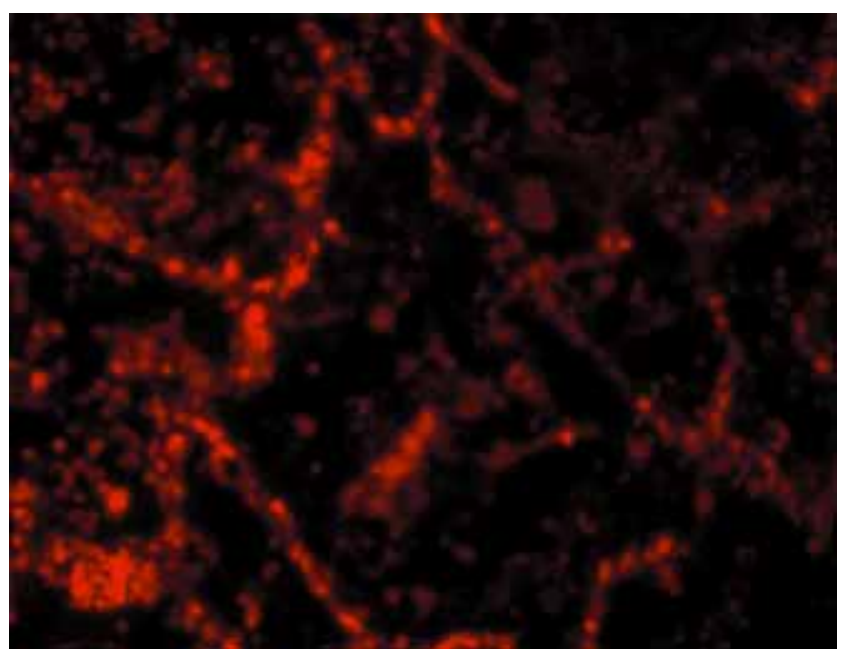

Рис. 3. Абсцесс легкого с секвестрацией. Деструктивные изменения базальных мембран альвеолоцитов, с сохранением коллаген-IV-позитивных структур в виде глобул. Иммуногистохимическая реакция на коллаген IV типа; × 400

В респираторном отделе легкого преобладали процессы фибринообразования над фибринолизом. При этом наблюдалось выраженное ограничение гнойно-деструктивного очага "молодым" и "созревающим" фибрином. В области фибринового блока фибриновые депозиты образовывали плотную сеть, в которую оказывались буквально "вмонтированы" клеточные популяции воспалительного инфильтрата. В его составе определялось умеренное количество нейтрофилов и макрофагов $(54,8 \pm 1,64 \%$ и $44,2 \pm$ $1,46 \%$ соответственно) и незначительное - клеток лимфоцитарного ряда $(0,98 \pm 0,03 \%)$. Подобное замыкание клеток в "фибриновый кокон", блокирование их функциональной активности приводило к невозможной элиминации "юного" и "молодого" фибрина, его созреванию и развитию склеротических изменений. Функциональная активность сохранялась у $58,80 \pm 2,22 \%$ нейтрофилов, $49,80 \pm 1,38 \%$ макрофагов и $60,80 \pm 1,73 \%$ лимфоцитов.

В просвете кровеносных сосудов обнаруживались массивные отложения фибрина, их проходимость была нарушена. Наблюдались слущивание эндотелия, набухание стенок сосудов, инфильтрация их клетками лимфогистиоцитарного ряда, конгломераты мононуклеарных клеток в просвете сосудов. Относительная площадь сечения сосудов составила $9,68 \pm 1,23$ мкм $^{2}$, количество сосудов на единице площади $-3,63 \pm 0,69$.

Расщепление и деструкция базальных мембран носили протяженный характер, занимая от 20 до $50 \%$ окружности микрососудов. В отдельных случаях наблюдались выраженные деструктивные изменения базальных мембран с сохранением коллаген-IV-позитивных структур в виде глобул (рис. 3).

Лимфатические сосуды визуализировались в меньшем количестве, отмечались протяженные изменения сосудистой стенки - деформация, слущивание эндотелиальных клеток.

Клиническая картина течения заболевания при вышеописанном морфологическом варианте характеризовалась "смазанным" проявлением симптомов. 


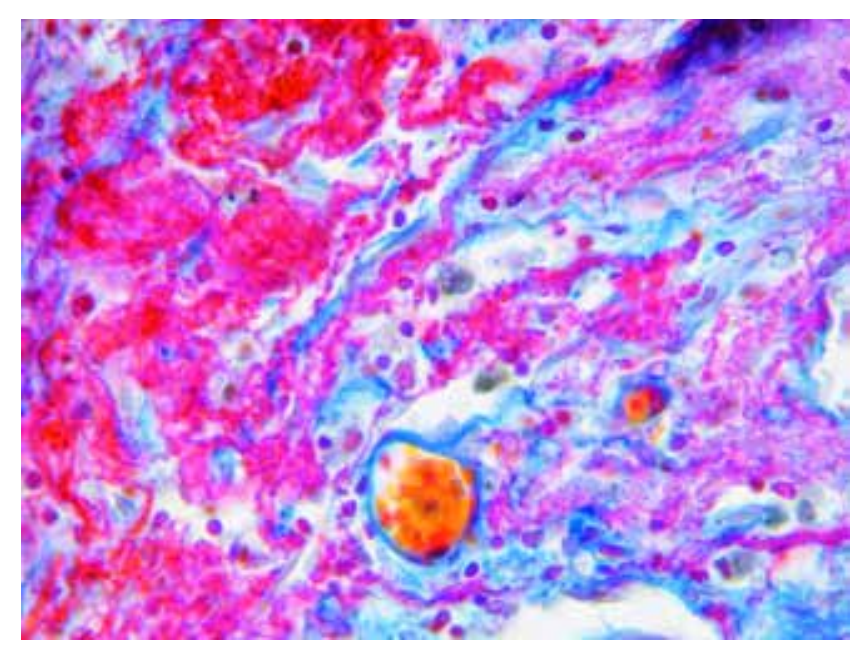

Рис. 4. "Фибриновый блок". Ускорение процессов созревания фибрина. Нежная сеточка молодого фибрина в просвете кровеносных сосудов. Окраска MSB; × 100

Локальные симптомы со стороны органов дыхания были слабо выражены. Боль в груди отмечали 57,1 \% больных. На кашель жаловались все обследованные пациенты, но > 200 мл мокроты в сутки отходило лишь у 17,8 \% из них. Признаки системной воспалительной реакции отмечены более чем у $1 / 2$ пациентов, тахикардия зарегистрирована у 92,9 \%, снижение систолического АД $<100$ мм рт. ст. и повышение температуры тела $>38{ }^{\circ} \mathrm{C}-$ более чем у $1 / 2$ пациентов. Тахипноэ диагностировалось у $1 / 3$ больных.

3-й морфологический вариант был выявлен у 15,9\% больных ОАЛ без секвестрации и у 7,1 \% с секвестрацией. На светооптическом уровне определялось слабо выраженное ограничение очага деструкции со слабым формированием фибринового блока из "молодых" фибриновых депозитов. Процессы фибринообразования и фибриностабилизации характеризовались тенденцией к ускоренному переходу "юного" и "молодого" фибрина в более зрелые формы (рис. 4).

Сосуды микроциркуляторного русла в большинстве наблюдений оставались проходимыми. Стенки сосудов и периваскулярно расположенные ткани легкого подвергались склеротическим изменениям. Отмечались выраженные протяженные деструктивные изменения базальных мембран сосудов микроциркуляторного русла.

Течение заболевания было тяжелым, часто процесс принимал распространенный или 2-сторонний характер. Локальные симптомы со стороны органов дыхания были ярко выражены: у всех больных отмечался выраженный болевой синдром, кашель, причем у 69,2 \% пациентов за сутки отделялось > 200 мл мокроты.

Признаки системной воспалительной реакции значительно более выражены, чем при 1-м и 2-м морфологических вариантах: тахипноэ регистрировалось у 76,9 \% пациентов, тахикардия - у 92,3\%, снижение систолического АД < 100 мм рт. ст. и повышение температуры тела $-\mathrm{y}^{2} / 3$ пациентов.

\section{Обсуждение}

Выявлено, что при ОАЛ каждый из представленных вариантов структурных преобразований респираторного отдела легких имеет определенную клиническую симптоматику, статистически значимо отличную от симптомов других морфологических вариантов.

При 1-м морфологическом варианте выраженность локальных симптомов со стороны органов дыхания была средней, в то время как системная воспалительная реакция проявлялась минимально. В целом реактивность макроорганизма была высокой: патологический очаг своевременно и полноценно отграничивался "свежим" и "молодым" фибрином; процессы фибринообразования, фибриностабилизации и фибринолиза протекали должным образом; клеточная поверхность фагоцитирующих клеток не блокировалась фибрином; признаки фибринообразования в сосудах микроциркуляторного русла легких отсутствовали или были минимальными. В результате обеспечивалось выполнение клеточными популяциями специфических функций, а также поступление к очагу деструкции лекарственных веществ в терапевтической дозе.

Особенностями клинической симптоматики больных со 2-м вариантом морфологических преобразований респираторного отдела легких являлись минимальные локальные симптомы со стороны органов дыхания и средне выраженные признаки системной воспалительной реакции. Вероятно, ответ макроорганизма на альтерацию был избыточным и сопровождался сбоем механизмов регуляции и компенсации. В патологическом процессе наибольшее значение приобретали массивные и неравномерные во временном отношении процессы фибринообразования с формированием "фибринового кокона" вокруг фагоцитирующих клеток, значительным снижением функциональной активности макрофагов, нейтрофилов и лимфоцитов. Выраженные структурные изменения сосудов микроциркуляторного русла, появление в них тромбов, иногда с гнойнонекротическими массами, блокировали кровоток и в совокупности нарушали нормальное разрешение патологического процесса.

3-й морфологический вариант характеризовался максимальной выраженностью локальных симптомов со стороны органов дыхания и системной воспалительной реакции. Анализ клинико-морфологической картины показал, что на фоне слабого ограничения гнойно-деструктивного очага "молодым" фибрином, ускорения процессов созревания фибрина и перестройки сосудов микроциркуляторного русла воспалительный процесс принимал распространенный характер с вовлечением 2-го легкого, что обусловливало тяжесть клинической картины.

\section{Заключение}

У пациентов с ОАЛ особенности структурно-функциональных нарушений респираторного отдела зависят от клинической формы заболевания, особенностей 
протекания процессов фибринообразования и фибриностабилизации, активности клеточных популяций воспалительного инфильтрата и проходимости сосудов микроциркуляторного русла.

Выявленные структурные закономерности клинико-морфологических преобразований могут способствовать выработке правильных тактических приемов в лечении. В случае морфологического варианта с преобладанием процессов фибринообразования, замыканием фагоцитов в "фибриновый кокон" рекомендуется использовать комплекс мероприятий, направленных на деблокирование микроциркуляторного русла. Медикаментозная стимуляция фагоцитов в этих условиях не представляется целесообразной в связи с блокированием рецепторов клеточных мембран фибрином.

\section{Литература}

1. Бисенков Л.Н., Саламатов А.В., Чуприна А.П. Острые инфекционные деструкции легких. В кн.: Бисенков Л.Н. (ред.). Торакальная хирургия: Руководство для врачей. СПб: Изд-во "ЭЛБИ-СПб"; 2004.

2. Шойхет Я.Н. Лечение острого абсцесса и гангрены легкого (актовая речь). Пульмонология 2002; 3: 18-27.

3. Гостищев B.K. Инфекции в торакальной хирургии: Руководство для врачей. М.; 2004.

4. Колесников И.С., Вихриев Б.С. Абсцессы легких. В кн.: Колесников И.С. (ред.). Руководство по легочной хирургии. Л.: Изд-во "Медицина"; 1969. 182-235.

5. Григорьев В.Г. Хирургия острого абсцесса и гангрены легкого. В кн.: Савельев В.С. (ред.). 50 лекций по хирургии. М.: Медиа Медика; 2003. 351-363.

6. Шойхет Я.Н., Рощев И.П., Седов И.П. Острый абсцесс легкого с секвестрацией. Пробл. клин. мед. 2006; 3 (7): $84-88$.
7. Шойхет Я.Н., Рощев И.П. Острый абсцесс легкого без секвестрации. Пробл. клин. мед. 2006; 4 (8): 58-64.

8. Шойхет Я.Н., Шкурупий В.А., Высоцкий Ю.А. и др. Особенности клинической морфологии клеточно-тканевых взаимодействий бронхолегочной системы у больных гнойно-деструктивными неспецифическими пневмонитами в условиях лечебной коррекции процессов фибринообразования и фибриностабилизации Хирургия, морфология, лимфология: науч.-практ. журн. (Бишкек) 2006; 3 (6): 15-22.

9. Hirshberg B., Sklair-Levi M., Nir-Paz R. et al. Factors predicting mortality of patients with lung abscess. Chest 1999; 115: 746-750.

10. Баркаган 3.С., Шойхет Я.Н., Бобоходжаев М.М. Связь эффективности лечения воспалительно-деструктивных заболеваний с деблокадой микроциркуляции в пораженных органах. Вестн. РАМН 2000; 11: 25-29.

11. Зербино Д.Д., Лукасевич Л.Л. Диссеминированное внутрисосудистое свертывание крови: Факты и концепции. М.: Медицина; 1989.

12. Abramoff M.D., Magelhaes P.J., Ram S.J. Image processing with image. J. Biophoton. Int. 2004; 11 (7): 36-42.

\section{Информация об авторах}

Шойхет Яков Нахманович - член-корр. РАМН, д. м. н., проф., зав. кафедрой факультетской хирургии Алтайского государственного медицинского университета; тел.: (3852) 68-50-23

Лепилов Александр Васильевич - д. М. Н., проф. кафедры патологической анатомии Алтайского государственного медицинского университета; тел.: (3852) 40-15-44; e-mail: lepilov@list.ru

Мотин Юрий Григорьевич - ассистент кафедры гистологии Алтайского государственного медицинского университета; тел.: (3852) 26-08-64; e-mail: ymotin@mail.ru

Лель Наталья Владимировна - ассистент кафедры гистологии Алтайского государственного медицинского университета; тел.: (3852) 26-08-64 